\title{
HOUSING, THE COMPUTER, AND THE ARCHITECTURAL PROCESS
}

\author{
ARthur R. Cogswell*
}

\section{INTRODUCTION}

So much has been written in recent years about the problems of the poor in America and the way in which these problems reinforce each other, that by now it has almost the ring of a truism to suggest that the needs of the poor are a "systcm" of needs. Yet it is inescapably so, and any consideration of solutions for one or more of these needs must begin with the fact that the problems faced by the poor are interwoven in a set of complex interrelationships, each supporting and reinforcing the others in their erosion of the energies and opportunities of those unfortunate enough to have been born in poverty.

It accomplishes relatively little to attempt to alleviate in an isolated fashion the effects of any one of the circumstances that surrounds such an individual or such a family. Indeed, it could be anticipated that the relief of one of the multiplicity of restraints surrounding such an individual might only open to him opportunities which would prove quickly to be illusory, with increased frustration and deeper bitterness the sole result.

The effort must begin somewhere, however; and there must be an implicit set of priorities in the situation. It would appear that housing is near the top of this list of priorities. If it is accepted that man is a physical organism, and that the behavior of a physical organism is a response to the conditions of its environment, it is difficult to deny that very thoughtful attention should be given to the enhancement of the quality and character of the physical environment in which we spend our lives, more particularly to the urban housing units which almost overwhelmingly determine the character of the physical surroundings in which most of our people spend most of their days. Winston Churchill said it very simply: "We shape our buildings, and thereafter they shape us."

\section{I}

Housing Environment and the Problems of the Poor

Considered in terms of the physical and emotional needs of the organism that is man, the dwelling units we have shaped might almost be characterized as punitive devices. Indeed, as physical organisms sensitive to and profoundly influenced by their surrounding environment, the human beings living in bad housing which is part of a defunct neighborhood forming a part of a chaotic and ill-functioning city, as most of them are, respond as we might reasonably have predicted them to: they throw up ambition, reject schools, engage in crime, allow their family structures to

* A.I.A.; Project Director, North Carolina Fund Low Income Housing Demonstration Project. 
dissolve, abjure the values of the general society which we present to them, and when the pressures of frustration mount in the presence of a spark of organization, they riot. If we wish the bulk of our population to become citizens who are both productive economically and sound politically, we must contrive to place them in an environment which will naturally produce such behavior. Better housing conditions and urban design cannot alone produce this result, to paraphrase Secretary Robert Weaver, but neither can these results be obtained without better housing and urban design.

Centuries ago the Roman architect Vitruvius delineated the three principal virtues which any piece of architecture worthy of the name must possess: firmness, commodity, and delight. We can today see much if we attempt to evaluate our housing, our neighborhoods, and our cities in these terms. In an overwhelming number of cases we see that not only are the structures of the neighborhoods and cities neither firm enough to be safe nor commodious enough to be efficiently used, but they are most certainly devoid of any suggestion of delight.

It is difficult to describe good housing without doing it in terms of a neighborhood or larger community, since it is in this context that good housing has meaning. Certain of the new towns being built across the country are examples of wellplanned housing arranged in well-planned communities, and what they provide for their inhabitants is a quantum jump in quality of life. Not only are the individual dwelling units light and well ventilated, easy to clean and maintain, satisfactorily equipped in a mechanical sense, efficiently planned to serve the needs of a family with decency and privacy, and possessed of a certain element of delight, but they are arranged in the landscape in meaningful relationship to each other, to the parks, playgrounds, and other green spaces, to neighborhood shopping centers, to recreational and cultural facilities, and to major lines of transportation to work centers and larger metropolitan areas.

The contrast between this and the grimy streets of tenements which crowd our major cities is a bitter one, particularly so when we realize that it is within our capability to do better than we are doing. It is a bitter one when we realize that the conditions implied by this contrast are producing public behavior of the most unhappy and unlawful sort. It is inescapable to the thoughtful observer that the burning, the looting, and the sniping which have occurred during the summer of 1967 are the simple result of a constellation of oppressive conditions, of which bad housing is a part, under which large numbers of our people have been living for over half a century, and with which they have finally become noisily impatient.

\section{II}

\section{Obstacles to Better Housing}

It is no small matter to analyze the present housing industry and suggest why it is such a laggard one in terms of technological advance and contribution to the 
public good, but it is possible to point to a number of factors which are of importance in the situation. Part of the problem lies in the fragmented nature of the building industry and the presence of a multitude of local building codes, most of which are different from any other. These two factors combine to inhibit the efforts of large industrial enterprises which have the financing required to develop industrial processes for producing good housing at minimum cost. In the face of code restrictions which vary from community to community across the country in a thousand ways, enterprises which might otherwise approach the national housing program with some expertise and innovation have held off.

Another item which has inhibited the design and construction of better housing, and particularly home ownership, is the traditional complex of financing and credit practices. Typically, it may take a person of small income several months to obtain a mortgage for the purchase of a small dwelling-if he is successful at all. If his credit background is at all clouded, or if his situation is in any way unorthodox, he will in all probability not obtain the mortgage. Even individuals in the low-income group whose recent credit history is clear, but who have had problems in the past, perhaps in youth, will in most cases be unable to obtain financing for a home. By contrast, financing practices in the mobile home industry are more flexible and resemble more than anything else the practices of the automobile industry. A prospective buyer can obtain financing for a mobile home in a matter of days, if not hours.

An associated problem here is the traditional association of the dwelling with the land upon which it rests. With greater industrialization of the housing industry, and a greater development of the capability of housing to be moved to new sites when local need changes, this indissoluble relationship between house and site may become less important and will lead to the increasing flexibility of financing practices for the small home owner.

This, however, is relative to the single-home market, a market which will inevitably become less and less a factor in the housing industry as time passes. The overwhelming need is for urban housing as the population shifts from a farm culture to an urban one. It is increasingly clear that the obstacles standing in the way of the construction of vastly larger numbers of urban housing units are rooted not only in the use of multiple code forms, in inadequate but traditional practices of land purchase and project financing, and in the failure of local governments to significantly tax undeveloped land as opposed to improved property, but, most importantly, in the failure of our building industry, for whatever reason, to utilize effectively the productive capacity of modern manufacturing techniques in the production of housing. And this failure is due, in turn, not to a lack of will but rather to an incapacity on the part of the designer, the architect, whose role it is to make the decisions that are involved in the assembly of materials and components into a design 
for a building. Industry has provided the architect in recent years with such an overwhelming multiplicity of materials and products that it is beyond human capacity to keep in mind enough information about performance and cost to choose for the design of a building the one combination of form, site, structure, mechanical equipment, and materials that represents the most satisfactory design for the budget available. It is simply too much for him to be able to judge performance against costs and to explore the complex interplay between all of the possible decisions and subdecisions.

In the absence of reliable facts, it is difficult to make a decision with any real confidence. Most of the decisions involved in designing a building relate to cost in one way or another, and are made with the probable or supposed cost in mind; but no one who has had any contact with the construction industry, however brief or small in scale, has come away from that experience without being made aware of the difficulty of predicting construction costs before the event. This is true of large-scale architectural and engineering projects as well as small, but it is nowhere more serious than in the housing industry. It is true that the housing industry, though of vast size, is a fragmented one with the overwhelming body of construction in the hands of thousands of relatively small construction firms. This has tended to retard innovation in construction practices, with small firms being both unable and uninterested in pioneering efforts aimed at cutting the costs of housing construction. Many other factors as well contribute to the slowness to change expensive and outmoded practices, but none is stronger than the inhibition imposed upon the architectural designer by his inability to predict reliably the costs of construction. This is true even when he is dealing with traditional materials and practices, and the problem is only compounded when he contemplates anything that involves innovation.

Moreover, as has already been mentioned, even when dealing with all of the multitudinous structural, material, mechanical, site-planning, spatial, visual, economic, and countless other considerations in developing a design for a housing project, the architect cannot possibly possess and effectively relate all the information required to enable him to make decisions leading to an optimum design for a given situation. It is simply beyond human capability.

It follows, then, that except by sheer good luck his design will be unnecessarily expensive, and probably less effective functionally than he intended, simply because he was unable to determine accurately which were the best elements to put into it from the standpoint of its own program requirements and budget. The upshot is that because of his lack of information the designer's buildings cost more than they should.

This means that less housing is now being built than the available funds would provide if the process of design were more efficient. The architect is intended to be a problem-solver, but he is woefully inadequate in attempting to solve twentieth century problems with seventeenth century tools. 


\section{III}

\section{A Computer Approach to Housing Design}

In the closing months of 1965 , the North Carolina Fund initiated a demonstration project which aimed at the development of an improved cost-analysis tool for the designer of low-income housing. With principal funding in the amount of $\$ 160,000$ from the U.S. Department of Housing and Urban Development, coupled with $\$ 30,000$ from the North Carolina Fund, work was begun in Chapel Hill and is scheduled to continue into late 1967 . The design system developed is to be field tested with the design and construction of a low-income housing project to be built during Ig68.

Known as the Integrated Building Industry System (IBIS), the design tool under development by the North Carolina Fund group does not attempt to change or restructure the basic design procedures traditionally used by the architect; but it does attempt to remove certain obstacles, supplying him with cost and performance information at critical decision stages in his development of a design. While it is true that an architect may, in using the IBIS system, refine a design while seated at a computer console rather than at a drafting table, the difference is more apparent than real. The decision making in which he engages during the development of his design is not changed, but it is materially assisted by the provision of hard information upon which those decisions can be realistically based. It is commonly thought by the layman that it has always been possible for the architect to make realistic design decisions, but this is not the case. Most often, his decisions are made on the basis of his own incomplete experience and written data that may or may not be recent and accurate, in supplement of which he can only employ intuition, imagination, and a certain measure of hope. In witness to the lack of effectiveness of these tools we have only to regard the great numbers of buildings surrounding us which have exceeded their budgets and fulfilled their purposes less than expected.

It is possible that the IBIS system will make a contribution in this area, since it will provide the architect with continuous reports on changes in construction cost resulting from design changes as he is developing his design. He immediately knows, therefore, whether a change he has just made-be it in plan, material, structure, or whatever-resulted in an increase or a decrease in total cost. It is expected that this information will contribute materially to the rationality of the architect's designs.

Briefly stated, the system is used in this fashion:

Step I-A three dimensional description of the building, interior and exterior, is stored in the machine as a reference base. The machine has already stored a data library consisting of materials, labor, and other costs to be encountered, with a wide range of materials and techniques used in low- 
income housing construction. These costs are taken from local field experience and are frequently updated.

Step 2-A list of materials and components for the building under analysis is entered by the designer and stored by the machine.

Step 3-The machine compares the three-dimensional description of the building automatically with the outline specifications mentioned above and produces a quantity survey and cost breakdown for the construction of the building.

Step 4-The designer may then modify his building design in dimension, form, material, location on its site, proportion, structure, or any of the other characteristics which he traditionally manipulates in developing an architectural design, and can immediately learn the economic consequences of the design changes as he makes them.

Working as described above, the architect can explore a much wider range of design alternatives than he could possibly do manually. In addition, he can readily learn in which direction lies the most economical and suitable solution for the particular problem at hand.

Working in this fashion, the designer of a low-income housing project can very readily investigate the effects of the major parameters in an architectural problem under analysis. It seems obvious that one of the major uses of the IBIS system will be in permitting a very thorough accelerated analysis of a project. This analysis would be an effective tool in making the very early decisions, such as site selection. Such decisions are frequently made when the general complexion of the project is still rather hazy, although the selection of one site over another may have the most powerful effects upon final construction cost for the project. It would be a very difficult and time-consuming process, for example, to develop a design from a close cost-analysis by conventional methods for each of several available sites, evaluating for each the implications of varying zoning conditions, subsoil conditions, topography, orientation, site size, vehicular and pedestrian access, and land cost, in order to determine which site out of many would permit the most satisfactory housing situation for least cost. As a result, site selection is often made on the basis of incomplete information as to the cost effects of the various options.

All of this could be accomplished rather easily, using the cost-analysis and design system described here. In a short time a design could be developed in its essentials for each site, a design which would approximate the economically optimum solution for that site, taking into account its particular features, so that the net results could be compared for each of the sites under consideration. Selection could then be made on a rational basis, the economic effects of the selection being known in advance. 
It is clear that at its present stage of development, IBIS does not achieve the fine resolution required to give cost-analysis on the most particular and detailed aspects of construction cost, such as those that arise from specialized detailing during the preparation of construction drawings. It is equally clear, however, that the system, dealing with a simple building type such as low-income housing, can explore cost alternatives very effectively short of this ultimate stage. It must be remembered that IBIS does not yield a market figure for construction costs. Only the market can do that. Rather, IBIS indicates the relative costs of construction alternatives: concrete frame versus bearing walls and open-web joists, for example, or one site layout versus another.

It should be noted, however, that the degree to which IBIS is able to explore the relatively detailed aspects of building design and the costs implied by those considerations exceeds anything currently available to the designer for use on a manual basis. The relative ease with which a great number of design variations can be explored, and the ready facility with which alterations in program requirements or standards can be examined in terms of cost/effectiveness, can be expected to upgrade substantially the quality of the design decisions made by an architect on a low-income housing project.

Indeed, the brief experience designers have had to date with machine-aided costanalysis suggests very persuasively that the presence of reliable cost information very early in the design stage frees a designer from inhibitions which have heretofore reduced his effectiveness. ${ }^{1}$

The discussion above suggests that major uses for the IBIS system may be found by others than the architectural designer. The capabilities of the system would be of great value to the institutional owner in planning future construction, in choosing sites for this construction, and in project management during the construction process.

The system could also be used by government agencies to evaluate proposed projects for compliance with various standards and planning requirements. Housing projects submitted for approval to the Federal Housing Administration, for example, could be readily and economically checked for the following items:

(I) Compliance with minimum property standards;

(2) Adequacy of mechanical systems;

(3) Compliance with local building code requirements;

(4) Appraisal.

Any checking operation requiring a substantial component of repetitive clerical operations could be adapted for performance by the IBIS system with significant savings not only in manpower but in the very substantial reduction of the required

\footnotetext{
${ }^{1}$ Thomsen, How High to Rise, J. AM. INstitute of ARchitects, April 1965, at 66.
} 
"turn-around" time for approval or disapproval. In many government agencies this would be of great value.

It should be noted here that cost is not the only factor for which a design may be optimized through the use of this system. Equally important might be spatial considerations, function of a particular nature, freedom from maintenance, or any other set of program requirements peculiar to the problem at hand. It is obvious that each building situation is a unique design problem with its own requirements to be resolved. If the significant parameters are more than several, and they almost invariably are, an automated information handling system such as this can be an aid of great value in its solution.

One of the more interesting ways in which the IBIS system could be used is in the cost-analysis of a project under differing code conditions. A project might be analyzed, for example, against the building code of one community and then against the code of one or more others, demonstrating the difference in cost for the same living accommodations imposed by different local building codes. It is possible that the IBIS system would be an effective tool in building code reform.

As implied earlier, the system might also be useful in demonstrating the relationship between costs and standards. It is frequently the case that a very slight increase in construction cost results in a substantial increase in performance or, conversely, that a modest cost saving results in a substantial sacrifice in quality. Using the procedures described here, it would be a relatively simple matter to determine which level of design standards represent the most effective investment for the project at hand.

It has been suggested in this connection that the problems of immediate versus ultimate cost could also be explored with great benefit. For instance, analysis of a particular project might indicate that, in view of limited funds on hand in the face of a great need for housing in a given locality, a design could be developed for minimum first cost which would imply somewhat higher long-term maintenance costs. Thus, in effect, a certain fraction of the total investment over the life of the property could be deferred until a later date and the maintenance costs be taken from the continuing income of the dwelling units.

On the other hand, it might be felt prudent in a particular case to minimize longterm maintenance and accept a greater first cost implied thereby. It is clear that it would be desirable to have both of these factors, minimum first cost and minimum long-term maintenance, taken together in the same project, but it is equally clear that they are almost always mutually exclusive. Some compromise must be struck between the two for each project according to the particular economic circumstances of the situation. What might be a wise choice for one would be imprudent for another. It is possible that the IBIS cost-analysis system would be a useful tool in determining just where the balance should be drawn for individual projects. 
The system as herein described has been brought to the point of prototype operation. The programs mentioned are in operation, and the capabilities outlined exist on a program-by-program basis. Work is currently continuing on program linkages and in the simplification of input techniques. Presently required are a number of forms on which the designer enters the design choices and outline specification information. This information must then be placed on punch cards for use with the machine. Several of these forms have now been programmed for use with the IBM 2250 graphic display unit and its associated light pen so that information may be entered with the light pen as a response to a printed question on the scope.

For maximum effectiveness and flexibility, the library of construction costs employed by the system should be frequently updated with data drawn directly from recent field experience by contractors. In the absence of a nationwide data collection network this is clearly impossible. Fortunately, however, the system is able to operate with substantial effectiveness using cost data prepared by professional estimators. It is hoped that in the future a data collection service will evolve, for such a service would permit maximum utilization of the inherent capabilities of the IBIS system.

Obviously the work described here is merely the first step in the development of a comprehensive information-handling system for the construction industry. The programs described here are adequate for dealing with a simple building type, the low-income house. But they should be regarded only as the first imperfect parts of a system that may eventually be expanded to include other building types and provide, quickly and economically, information required by the architect in making design decisions; by the owner in making decisions affecting his current and projected investment; by government agencies acting as evaluator, sponsor or owner; by the contractor who will use the same information for bidding, for scheduling, for ordering materials and managing labor; and for all of these individuals in monitoring the aspects of the construction process with which they are concerned.

\section{IV}

\section{Extensions of the Computer Approach}

The IBIS system as described herein is a very crude and cumbersome instrument, but it is a first step. To achieve maximum usefulness in the future, however, work must be concentrated in several areas. First, the system must develop a capability for suggesting a solution. As presently constituted, it can only wait for the operator to make an intuitive choice when a change is to be made. It would be very useful if the machine were able to survey a set of performance requirements and then select a material, structure, or siting situation or a plan form which best solved the problem at hand and submit this selection for editing by the designer. Only if the machine is given this capability can the architect concentrate again upon his primary 
function: that of exercising an informed judgment in the organizing of an architectural solution. The machine can perform better than he the trivial operations which currently occupy so much of an architect's time. The checking, catalog searching, ineffective cost estimating, dimensioning, drafting of repetitive detail, and countless other minor clerical tasks occupy the greater part of his time and leave him neither the opportunity nor the energy for concentrating upon the more essential elements of the work at hand.

In addition, the graphic input and output capabilities of the IBIS system should be expanded. The capability of accepting graphic input and of producing output in the form of drawings seems critical for architectural use on a wide scale.

Finally, the scope of the data employed may eventually be extended to include not only cost and performance information but also data reflecting more of the parameters having significant effect upon the construction environment. It is anticipated also that eventually it may be possible to include significant information from the behavioral sciences which bear upon architectural design. At present, research in the behavioral sciences is not so defined as to be of any direct benefit to the designer of low-income housing, and he must rely upon the assistance of knowledgeable consultants in sociology and psychology.

The long-term implications of development such as the one described here are not clear, but they are many. With regard to housing, it is safe to say that the designs which are produced will be less expensive and more functional, as well as more pleasurable to live in. The budgets will be more prudently spent with the result that more amenities will be possible. The architect will find himself less preoccupied with uncertainties as to cost and practicality and will be able to devote a greater portion of his effort to thoughtful consideration of the intangible aspects of design which give meaningful character to a living situation.

On a larger scale there are further implications suggested by this approach to problem solving of a technical sort. It should, for example, be possible to treat problems of larger scale than building design.

If it can be reasonably suggested that the complex needs of the poor form a system, then it can also be stated with some conviction that the resources and capabilities of the various municipal, county, state, federal, and private agencies form a system which can be effectively coordinated for the solution of these needs for the general good.

Currently these resources are poorly coordinated, if at all, in the sense of a total system, and the people are ill served. If the goal of the society can be stated as the continuing improvement in the level of satisfaction of the physical and emotional needs of the people, then it seems prudent to adopt techniques which will permit the effective management of this very complex system for the general benefit.

It is difficult to be very specific about these techniques at present, although rough prototypes do exist which may provide us with some guidance. The procedures being used for the building design cost-analysis described above will perhaps be of some 
use; but certainly the most important techniques available to us today in developing a comprehensive management system for the utilization of a state's resources are those currently in use in large industrial enterprises, particularly those scattered over a wide geographic area.

A quick look at these management systems convinces us of two things: ( $r$ ) they are effective-indeed, the enterprises of which they are part could not operate effectively without them; and (2) the operations and resources which we wish to coordinate on a large scale for the public good are neither so dissimilar in character nor so complex as to be unmanageable by the same methods.

It is possible to imagine that such an effort could lead to the establishment, probably in the office of the state department of administration, of a position occupied by an individual who would function as a systems coordinator. This person, with a staff of research associates, would be in daily touch with every aspect of the operation of the state, the condition of its economy and its commercial structure, the conditions and trends reported by the social service and welfare agencies, its educational system, health trends and conditions, the state of its agriculture and associated markets, its relations with various federal programs and agencies, and every other accessible source of information bearing upon the facilities of the state or the needs of its people. This information would be constantly maintained and updated in a computer-based real-time census which would permit the systems coordinator rapidly to interrogate this data base to recall information required for decision making.

With a much more intimate knowledge of the functioning of the many facilities operating in the state, both within government and out, than could be maintained by anyone otherwise occupied in one of the top policy-making positions, and capable of interrogating a machine-stored data library maintained as a real-time census, this systems coordinator would be in a position to ( $\mathrm{I}$ ) detect developing problems before they became serious enough to need crisis treatment, and (2) effectively coordinate whatever resources existed within the state which could appropriately be brought to bear upon the problem at hand.

For example, if the housing needs of a certain income group began to rise in a locality where the inventory of available housing was insufficient to satisfy this need, this fact would immediately be flagged by the information-handling system described above, and action could be initiated immediately to stimulate new construction of appropriate housing in that locality. As matters now stand, the housing needs of this hypothetical group remain unknown until some considerable time after the fact, when they are made known by some untoward incident which reveals the by then drastic need. This is inefficient both in terms of the management of available resources and in terms of the distress to which the people concerned are subjected. It is particularly bad in terms of business, since a housing market has existed for some time, undetected and unserved. 
Conclusion

In summary, it suffices to state that the problem of supplying decent and pleasant housing for a growing population, a population which is increasingly restive and vocal in the presence of intolerable urban housing conditions, is a central one for us today and is very close, indeed, to the heart of the question of the continued successful maintenance of our urban complex and our society as we know it. It is certainly one of the closely-related handful of problems which together define the character of poverty in America today. The decision making tool described in this article is one step toward a more rational utilization of the resources which we have for the easing of one very critical aspect of this complex of problems. It is hoped that field testing will prove its efficacy and permit its wide application, together with the other new techniques springing from other disciplines which will be required in the general effort to lift low-income groups beyond the reach of those corrosive conditions historically associated with the situation of poverty. 